\title{
College English Teachers' Sense of Responsibility-a Research Based on Schlenker's Triangle Model of Responsibility
}

\author{
Tuanhua Lu \\ School of Foreign Languages of Xianyang Normal University, Xianyang, Shaanxi, 712000
}

Keywords: College English teachers; Sense of responsibility; Model

\begin{abstract}
Teachers' sense of responsibility is one of the determinants of college English teaching. However, its importance has been overlooked by most of current researches, hence this topic is insufficiently studied. The Triangle Model of Responsibility proposed by Schlenker precisely forecasts and explores a participant's sense of responsibility. Based on the Model, this research maintains that, in college English teaching, teachers' sense of responsibility is determined by three factors: recognition of their identities as teachers, teaching regulations and teaching activities. And the Model also yields great implications for researches into college English teachers' sense of responsibility.

People get used to exploring the connotation of "responsibility" from legal and moral perspectives. Similarly, college English teachers' "responsibility" can also be interpreted both legally and morally. The so-called legal responsibility refers to the obligations that teachers must perform as specified in laws and regulations. "Moral responsibility" indicates that college English teachers should not only play such roles as "gardeners" or "candles" defined by the society, but also must recognize teaching as "a profession" and observe restrictions on their behaviors in performing their professional duties. Setting "college English teachers' responsibility" at the moral respect, this research will mainly explore how to motivate and actualize college English teachers' sense of responsibility in their teaching practice.
\end{abstract}

\section{College English Teacher's Sense of Responsibility and Their Teaching Responsibility}

Sense of responsibility, with a psychological source, refers to the belief and emotion that an individual should take responsibility for himself and the society. Characterized by self-consciousness, it is also known as responsibility consciousness or responsibility mentality. It should be noted that the two terms, responsibility and sense of responsibility, are differentiated but interrelated. "Responsibility", with a legal view, requests an individual to undertake the legal liability from his undesirable behaviors, while "sense of responsibility" stresses one's morality with a psychological consideration. In brief, "sense of responsibility" is an individual's attitude towards his responsibility.

\section{College English Teaching as the Primary Responsibility}

Since the first year, colleges and universities have assumed the responsibility of "imparting knowledge", which is actualized by various educational and teaching practices. With scientific and technological development, colleges are gradually exerting their importance in "scientific researching". In the meantime, the conflict between teaching and scientific researching has also become one of major conflicts in colleges and universities. However, in essence, teaching and scientific researching are interrelated and united. Therefore, teaching and researching must be closely combined as a whole, and thus colleges and universities can genuinely spread and impart knowledge.

Most of colleges and universities separate researching from teaching or make them mutually exclusive, or even set researching over teaching. To curb that fault, many scholars propose restoring teaching as teacher's primary responsibility. When education advances, colleges and universities' responsibilities have drawn more and more attention. As for their internal responsibilities, they should relentlessly ensure and improve teaching in order to fully fulfill their duties for the sake of students' growth. College English teachers manage and conduct teaching activities, which actually shows how such responsibilities are undertaken and achieved. Therefore, the evaluation on colleges 
and universities' implementation of their internal responsibilities should involve college English teaching.

\section{Sense of Responsibility as a Major Indicator of Teaching Performance}

Besides professional knowledge, theories and study methods, college students should also acquire English proficiency, thus they can better serve the country and the people. However, their English achievements, professional theories and study methods are hinged on whether college English teachers can properly and thoroughly deliver English courses. In the meantime, their sense of responsibility for the teaching profession also has an influence on their specific teaching activities, and is an indicator of their job performance.

In addition, the implementation of English teaching is partly decided by teachers' competence. English teacher's teaching competence is comprehensive and is also known as the comprehensive teaching quality. College English teacher's teaching competence refers to their abilities to deal with teaching events and carry out teaching activities, including handling classroom accidents, upgrading teaching methods, interpreting teaching materials, scheduling class progress and renovating professional knowledge. Their teaching competence fully reveals their comprehensive quality. When the teaching teams vigorously improve their quality, every teacher has remarkably progressed in his or her knowledge and skills. Under such circumstance, teachers' sense of responsibility for their profession prominently contributes to their teaching competence. Those teachers without it would be sluggish in teaching, while those with a strong sense, though lack of higher degrees, will relentlessly improve themselves out of their responsibility. Therefore, sense of responsibility thoroughly reflects college English teachers' responsibility for their profession.

\section{Theories to Develop a Model of Sense of Responsibility for College English Teachers}

Sense of responsibility, an abstract concept, needs to be specified for the model of sense of responsibility for college English teachers. Schemer's Triangle Model of Responsibility (hereafter referred as TMR), forecasting and exploring an actor's sense of responsibility, lays a solid theoretical foundation for specifying sense of responsibility. TMR consists of three elements (see Fig 1): settings (or rules), events, and activity implementers (specifically their beliefs, roles and moralities). Accordingly, sense of responsibility is manifested when an activity implementer figuring out their identity conduct some actions to handle an event in particular settings.

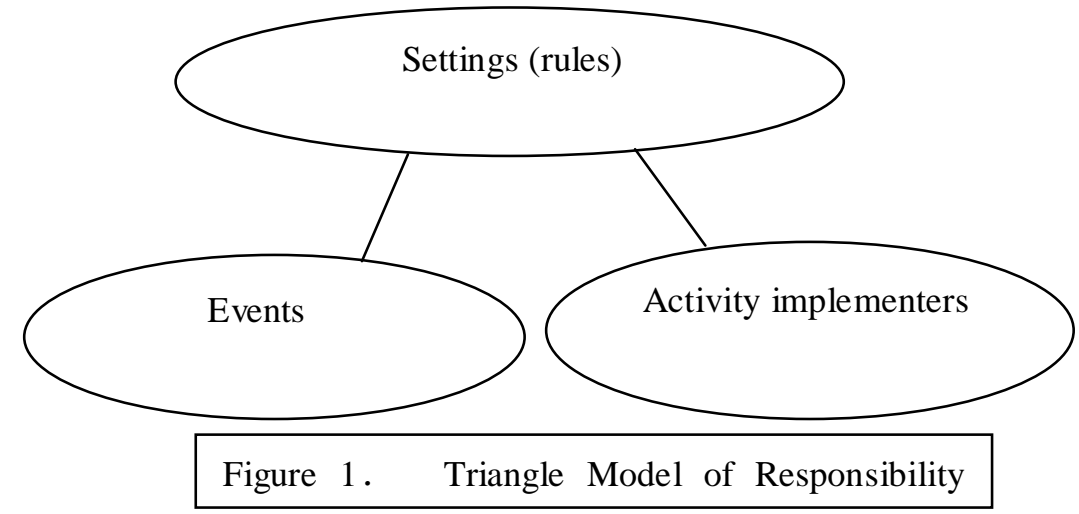

With TMR, Schlenker explores factors contributing to sense of responsibility in particular settings. He claims that stronger sense of responsibility derives from three sources: specific and clearly-defined rules (the linkage between rules and events), actors' proper conducts consistent with their identities (the linkage between identities and rules); impacts of the conducts on concluding the events (the linkage between identities and events). In brief, with three pairs of linkage, TMR explicitly specifies the connotations of "sense of responsibility" and its contributing factors. "Sense of responsibility" effectively bridges and joints the three elements in TMR. 


\section{The Model of Enhancing College English Teachers' Sense of Responsibility}

Schlenker's TMR has been verified by scholars and experts and is therefore of some reliability. Based on TMR, this research develops the Triangle Model of Sense of Responsibility for College English Teachers (hereafter referred as TMSRCET, shown as in Fig.2) to enhance college English teachers' sense of responsibility.

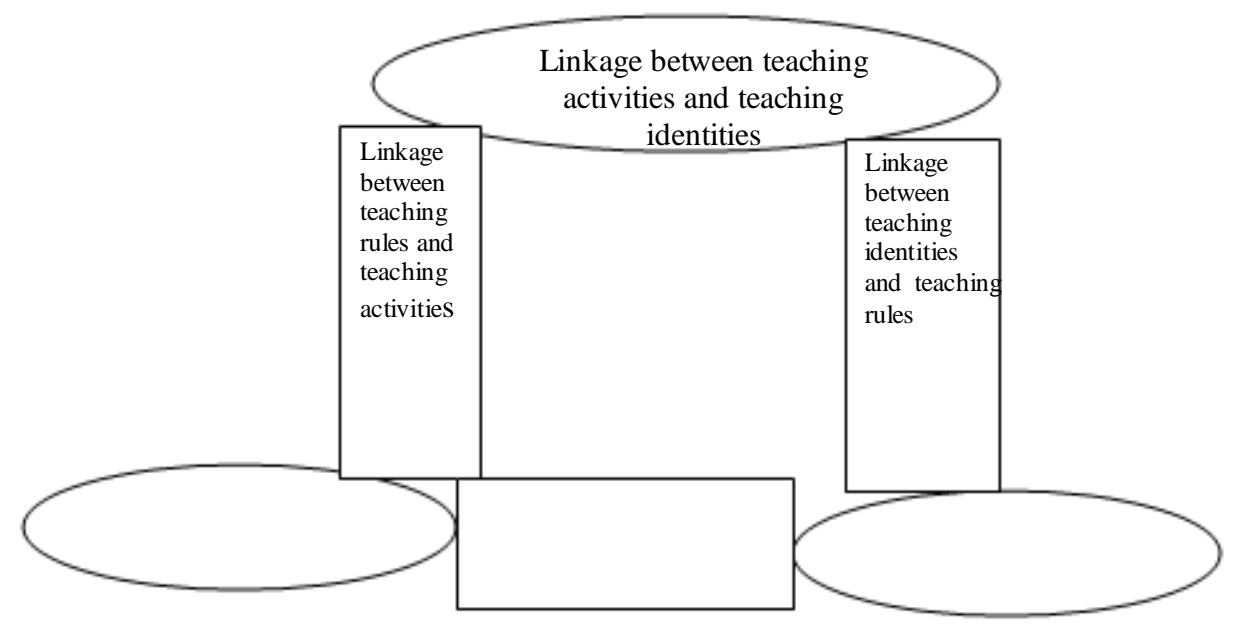

Figure 2. Triangle Model of Sense of Responsibility for College English Teachers (TMSRCET)

\section{Specifying Teaching Rules for College English Teachers}

As shown by TMSRCET in Fig. 2, the linkage between rules and activities (events) reaches the peak when teaching objectives and rules are clearly defined, which also dramatically cut the probability that the actor evades his due responsibility. Therefore, to effectively supervise college English teaching, teaching rules must be explicitly specified and regulated at the first. For the sake of each college English teacher, the rules should be made as complete, concrete and inclusive as possible, so that they can guide and direct all the teaching steps and stages. It should be noted that the specialties of college English as a discipline should be considered when the rules are made. For team collaboration, the teaching rules should entail incentive terms, which can encourage teaching members' enthusiasm to advance and communicate. The teaching effect should be involved into teachers' performance evaluation lest teaching be outweighed by researching.

Meanwhile, researches detect nervousness or anxiety within actors which generally induces disappointing results when actors are expected to behave desirably but with vague rules. Similarly, TMSRCET holds anxiety, shyness, and timidity can be attributed to emotional and mental fluctuation generated by the absence of instruction for which ambiguous teaching objectives and rules should be blamed. Therefore, psychological counseling is of great significance in that case. College English teaching, essentially a kind of art, is influenced not only by such factors as teachers' knowledge reserve and teaching methods, but also by their teaching experience from long-term teaching practices. Many young English teaching green-hands are troubled and puzzled by various difficulties and problems. If colleges and universities set a platform for them to communicate with and learn from those experienced, or provide them with mental counseling and guidance, they will continuously make progresses in their teaching and improve their sense of selfand social responsibility as well.

\section{Exerting an Individual's Value to the Team of College English Teachers}

In TMSRCET, the linkage between identities and activities (events) will drive a college English teacher to observe more rules when he is more competent to conduct and manage teaching activities alone[5]. Generally speaking, when one expects to obtain some achievements from his own actions, the linkage between identities and events will reach the peak, while a weaker linkage occurs when actions are unpredictable, occasional or uncontrollable. Hence at one hand, college English teaching 
is actually collective which is impossible without the participation and guidance of a team of English teachers, and at the other hand it fully reflects the great value and contribution of each individual. Firstly, college English teaching is collective in that the teaching team joins and shares each teacher's wisdoms publicly. The team should encourage an individual to learn and adapt various wisdoms to his capacity and specialty out of the principle of seeking similarities while reserving differences. Secondly, praising and punishing should be distinct enough. Contributions should be awarded and misconducts be penalized either spiritually or physically to highlight everyone's value. The award for a teacher should consider and balance two sides - the individual and the team. The performance evaluation should keep an eye not only on the collective achievement of the team as a whole but also on an individual's devotion. The evaluation on one's teaching should cover his teaching, the course and his professional. By participating in group activities, a single teacher can witness his contributions to the team and exert his influence on others. Praising an individual's outstanding actions or achievements can effectively motivate others' sense of responsibility and passion to serve the team.

\section{Enhancing College English Teachers' Identities}

The linkage between identities and rules in TMSRCET shows a teacher's sense of responsibility is significantly positively correlated with his self- and social identities. The clearer the rules and the more specific the identity requirements and restrictions on the actor are, the stronger the linkage between identities and rules would be. The linkage turns weaker upon vague rules and requirements. Therefore, this research proclaims that college English teachers' identities should be enhanced. A team's joint collaboration is indispensable for a teacher to pinpoint his identities. The establishment of one's identities not only demands a general system, but also his vigorous efforts. According to TMSRCET, when conflicts between rules and an actor's identities arise, the rules must be rationally rechecked and sifted. Thus, when examined against researching, teaching must be granted with priority and ranked as the core. The harmony and balance between teaching and researching is based on enough attention to researching, but more attention to teaching. The linkage between a teacher's identities and teaching rules is conducive to developing his sense of responsibility.

\section{Acknowledgements}

[Fund Source]This paper is funded by the Project of Talents of Xianyang Normal University (No.: XSYQL201510). This paper is funded by the 13th Five-Year Plan Fund of Educational Scientific Research of Shaanxi Province (No.: SGH17H179).

\section{References}

[1] Tang Zhong. Application of Self-education in Modern Education Technology of College Teacher [J]. Continue Education Research, 2011 (01).

[2] Ning Xiaoran. A Research on Problems about College Teacher's Sense of Responsibility [J]. Higher Education Exploration, 2013 (10).

[3] Yao Xiujuan. Teaching Responsibility: Primary Responsibility of College Teacher [J]. Heilongjiang Researches on Higher Education, 2014 (02).

[4] Li Ming. A Research on Connotation, Structure and Integration of Responsibility [J]. Psychological Development and Education, 2011 (09).

[5] Qu Zhengwei. Teacher's "Identity" and "Identity Recognition" [J]. Research in Education Development, 2009 (06).

[6] Zhai Zhao. Three Debates over Teacher's Sense of Responsibility [J]. Journal of Tianjin Normal University (Elementary Education Edition), 2003 (09).

[7] Wang Shouren. Promotion Methods and Means of Development of College Foreign Language Teachers [J]. Foreign Language Learning Theory and Practice, 2017 (05).

[8] Zhu Jixiang. A Research on Problems and Countermeasures for Professional Development of College Teachers [J]. Continue Education Research, 2015 (8). 
[9] Lu Tuanhua. A Research on Performance Evaluation Index System of College Foreign Language Teacher from Multi-dimensional Perspective [J]. China Adult Education, 2014 (05).

[10] Hua Jianzhong. Current Situation of Academic Evaluation on Teaching of College Teachers in China [J]. Higher Education Exploration, 2010 (12).

[11] Yang Yuanyan. A Research on College Teacher's Participation in University Decision-making Mechanism [J]. Jiangsu Higher Education, 2015 (03).

[12]Pang Xiaodong. A Research on Connotation and Generative Mechanism of Teacher's Curriculum Standard Consciousness [J]. Teacher Education Research, 2011 (06). 